\title{
Choosing the right angiotensin-receptor blocker for patients with diabetes: still controversial
}

\author{
Mark E. Cooper MBBS PhD
}

See related research article by Antoniou and colleagues on page 1035 and at www.cmaj.ca/lookup/doi/10.1503/cmaj.121771

$\mathrm{T}$ he rise in diabetes continues unabated, and the major burden of this condition is its macrovascular complications. Current guidelines emphasize the importance of addressing multiple risk factors implicated in the pathogenesis and progression of these complications. Treatment should thus include optimal glycemic control and aggressive management of hypertension and dyslipidemia, as was clearly shown in the Steno-2 study. ${ }^{1}$

For the last 2 decades, interruption of the reninangiotensin system using either angiotensinconverting enzyme (ACE) inhibitors or angiotensin-receptor blockers has been the firstline choice for reducing blood pressure in patients with diabetes, particularly in those with evidence of renal disease. ${ }^{2}$ Benefits over other classes of antihypertensive agents have been reported with respect to microvascular complications including nephropathy and, more recently, retinopathy. ${ }^{3}$ However, the main focus of studying these agents has been their effects on macrovascular complications, although the superiority of targeting the renin-angiotensin system over other blood pressure-lowering strategies remains unproven. This issue remains unresolved, despite a number of theoretical reasons for a difference in the cardiovascular effects between ACE inhibitors and angiotensin-receptor blockers, including in the setting of diabetes. Indeed, the ONTARGET study failed to identify any significant differences in cardiovascular outcomes between use of the ACE inhibitor ramipril and the angiotensin-receptor blocker telmisartan in a large cohort of patients at high risk of cardiovascular disease, including a substantial number of patients with type 2 diabetes. ${ }^{4}$ This issue continues to be controversial. Indeed, a recent meta-analysis has suggested a potential superiority of ACE inhibitors over angiotensin II antagonism. ${ }^{5}$ However, because this report was a meta-analysis rather than a clinical trial, such data must be interpreted with caution.

Another controversy that remains to be resolved is whether there are differences among the various angiotensin-receptor blockers avail- able to clinicians and widely used in this population of patients. Angiotensin-receptor blockers are often used in patients with diabetes as a result of the positive results from trials that suggested that these agents were renoprotective in type 2 diabetes. ${ }^{6}$

A recent retrospective study reported in $C M A J$ has provocatively suggested that 2 angiotensin-receptor blockers, valsartan and telmisartan, may afford superior cardiovascular benefits, specifically in reducing the risk of admission to hospital for acute myocardial infarction, stroke or heart failure, when compared with other widely prescribed drugs in this class such as losartan, candesartan and irbesar$\tan ^{7}$ The authors are cautious in their interpretation of the data, which represents an analysis of more than 54000 patients with diabetes started on an angiotensin-receptor blocker, with a composite primary outcome of admission to hospital for either acute myocardial infarction, stroke or heart failure. Secondary analyses suggested the superiority of valsartan and telmisartan over other angiotensin-receptor blockers with respect to lowering the risk of heart failure.

The importance of these results remains to be determined, and their reproducibility is unlikely to be formally tested in an appropriately designed randomized trial. The authors suggest that the potential benefits of telmisartan may be related to its reported action as a partial peroxisome proliferator-activated receptor- $\gamma(\operatorname{PPAR} \gamma)$ agonist, ${ }^{8}$ an effect that could lead to improved

\section{KEY POINTS}

- Macrovascular complications are the major burden of diabetes.

- In addition to optimal glycemic control, diabetes treatment should include aggressive management of hypertension and dyslipidemia.

- Whether angiotensin-converting enzyme inhibitors and angiotensinreceptor blockers have different cardiovascular effects remains unresolved.

- Without appropriately designed randomized controlled trials, there is scant evidence to support using any particular angiotensin-receptor blocker for cardioprotection in patients with diabetes. 
metabolic profile, as shown by lower glucose levels and reduced insulin resistance. Telmisartan's role as a PPAR $\gamma$ agonist has been clearly shown in vitro; ${ }^{8}$ however, whether this action translates clinically to improved metabolic control has been difficult to confirm in appropriately designed studies in humans.

Furthermore, the assumption that PPAR $\gamma$ agonism would lead to improved cardiovascular outcomes may be flawed. For example, the PPAR $\gamma$ agonist rosiglitazone is associated with a potentially deleterious effect on cardiovascular outcomes. ${ }^{9}$ Not only is rosiglitazone associated with fluid retention (a well-reported adverse effect of this class of drugs) and, in some patients, overt heart failure; it has a potential association with increased cardiovascular events as a result of macrovascular disease, as shown by increased risk of myocardial infarction. ${ }^{9}$ In addition, pioglitazone, another PPAR $\gamma$ agonist, is associated with increased heart failure, although a deleterious effect on macrovascular outcomes is unlikely. The PROACTIVE study suggested a potential cardiovascular benefit for pioglitazone, although a positive outcome on the primary outcome was not reached in that trial. ${ }^{10}$ Thus, although Antoniou and colleagues have attributed the potential benefit of telmisartan as described in their analysis to its action as a PPAR $\gamma$ agonist, ${ }^{7}$ this conclusion is unlikely because PPAR $\gamma$ agonism would not be predicted to lead to a reduction in heart failure.

The putative benefits of valsartan are even more difficult to explain. This drug is not generally considered to be the most potent in its class and is not known to be a strong PPAR $\gamma$ agonist. Antoniou and colleagues concede that this result was unexpected and that part of the benefit of valsartan may have been related to the doses used by the study participants. ${ }^{7}$ Other suggested actions include inhibition of platelet aggregation and effects on the anti-inflammatory hormone adiponectin. However, there is no clear evidence that such potentially antiatherosclerotic actions are not seen with other angiotensin-receptor blockers.

The clinical situation for type 2 diabetes is continuously changing, with an ongoing reduction in the overall rate of cardiovascular events. New treatment paradigms are being considered for the condition, particularly with respect to glu- cose lowering, as a result of the advent of newer classes of glucose-lowering agents in wide use, such as incretin analogues and dipeptidyl peptidase 4 inhibitors, or drugs that have recently been introduced into clinical practice, such as sodiumglucose cotransporter 2 inhibitors. ${ }^{11}$

For now, whether certain angiotensin-receptor blockers are more cardioprotective than others in type 2 diabetes remains to be seen. Although Antoniou and colleagues' retrospective study has generated some intriguing results, without appropriately designed randomized controlled trials, there is scant evidence to support preferring one drug in this class over another for patients with type 2 diabetes. Thus, the results reported by Antoniou and colleagues would require further work before they could be translated into changes in the current guidelines for the management of type 2 diabetes and its complications.

\section{References}

1. Gaede P, Lund-Andersen H, Parving HH, et al. Effect of a multifactorial intervention on mortality in type 2 diabetes. $N$ Engl $J$ Med 2008;358:580-91.

2. Bhattacharyya OK, Shah BR, Booth GL. Management of cardiovascular disease in patients with diabetes: the 2008 Canadian Diabetes Association guidelines. CMAJ 2008;179:920-6.

3. Sjølie AK, Klein R, Porta M, et al. Effect of candesartan on progression and regression of retinopathy in type 2 diabetes (DIRECT-Protect 2): a randomised placebo-controlled trial. Lancet 2008;372:1385-93.

4. ONTARGET Investigators, Yusuf S, Teo KK, et al. Telmisartan, ramipril, or both in patients at high risk for vascular events. N Engl J Med 2008;358:1547-59.

5. Ruschitzka F, Taddei S. Angiotensin-converting enzyme inhibitors: First-line agents in cardiovascular protection? Eur Heart J 2012;33:1996-8.

6. Brenner BM, Cooper ME, de Zeeuw D, et al. Effects of losartan on renal and cardiovascular outcomes in patients with type 2 diabetes and nephropathy. N Engl J Med 2001;345:861-9.

7. Antoniou T, Camacho X, Yao Z, et al. Comparative effectiveness of angiotensin-receptor blockers for preventing macrovascular disease in patients with diabetes: a population-based cohort study. CMAJ 2013;185:1035-41.

8. Benson SC, Pershadsingh HA, Ho CI, et al. Identification of telmisartan as a unique angiotensin II receptor antagonist with selective PPAR $\gamma$-modulating activity. Hypertension 2004;43:993-1002.

9. Singh S, Loke YK, Furberg CD. Long-term risk of cardiovascular events with rosiglitazone: a meta-analysis. JAMA 2007;298: 1189-95.

10. Dormandy JA, Charbonnel B, Eckland DJ, et al. Investigators PR. Secondary prevention of macrovascular events in patients with type 2 diabetes in the PROACTIVE Study (PROspective pioglitAzone Clinical Trial In macroVascular Events): a randomised controlled trial. Lancet 2005;366:1279-89.

11. Tahrani AA, Bailey CJ, Del Prato S, et al. Management of type 2 diabetes: new and future developments in treatment. Lancet 2011;378:182-97.

Affiliation: Diabetes Division, Baker IDI Heart and Diabetes Institute, Melbourne, Australia. 